\title{
Exploring Stance and Engagement Features in Discourse Analysis Papers
}

\author{
Leila Sayah \\ English Department, Ferdowsi University of Mashhad, Mashhad, Iran \\ Mohammad Reza Hashemi \\ Department of English and Literature, Faculty of Letters and Humanities, Ferdowsi University of Mashhad, Iran
}

\begin{abstract}
Stance and engagement features as the necessary devices in structuring the correspondence between text, readers and social context primarily illuminate the main subtleties of rhetorical functions in most academic writings. Although they have received a pivotal importance in many recent studies, not all the features of stance and engagement have been investigated in different fields of studies. To fill the gap, to some extent, ninety discourse articles published in ISI and non ISI journals on sociology, linguistic and education were selected and analyzed in terms of Hyland (2005) model. We found significant differences in developing features like hedges, self mention and appeals to shared knowledge in either of them. Over application of boosters or hedges observed in some articles attains the necessity to realize the significant preferred communicative style, interpersonal strategies, and organized preconceptions of each researcher in writing discourse analysis articles. We further suggested developing an exclusive content highlighting socio- cultural perspectives as well as providing the students with subtle interactive stance and engagement features in promoting the writers' discursive persona in academia.
\end{abstract}

Index Terms - stance, engagement features, shared knowledge, self mention, booster

\section{INTRODUCTION}

There had been influential researches dealing with cross -linguistic and cross -cultural differences using stance features -mainly hedges and boosters - asserting socio- cultural or style differences among a variety of languages. Stance features have been analyzed in different fields and each highlighted the significance of interdisciplinary features within languages' persona to "project both personal modesty and honesty" (Salager-Meyer, 1994). To convince hearers and readers is to use as much vagueness and tentativeness that one could afford to persuade academic members of different disciplines with the new comer's ego stance identity -the stance that seems to be one of the basic essentials in research writings and as Hyland (1996) asserts "writers also need to present their claims cautiously, accurately and modestly to meet discourse community expectations and to gain acceptance for their statements" (p. 477).

Though our confidence, attitudes, shared knowledge, persuasiveness and mutual interaction with the reader (Hyland, 1994, 2000, 2002, 2005, 2008; Salager-Meyer, 1994; Prnice et al, 1982) as the main features of stance and engagement could significantly influence our style or writing, very few studies investigated the mentioned features in different life domains (Hyland, 2000, 2005; Serholt, 2012; Pishghadam, \& Norouz Kermanshahi, 2012; Taki \& Jafarpour, 2012). A large corpus of studies was dedicated to certain features as hedges and boosters as two major communicative devices. To this end, and since different sections of research articles highlight a 'variety of rhetorical functions which are realized by various linguistic resources' (Salager-Meyer, 1994), it was determined to focus on the introduction section of different research articles -the fundamental section in which the writers initiate the main concepts when summarizing the significance of the study, objective, the research questions, and the problems of the previous studies or as SalagerMeyer (1994) puts it the introduction part allows researchers to establish an "early niche" for their research.

In addressing this issue, it was attempted to examine stance and engagement features as "both of a writer's argument and of a disciplinary context in an unfolding dialogue" (Hyland, 2005) to reveal any possible development of power, "authoritativeness or modesty derived from voice as the cultural inheritance" (Hyland, 2008), possible imitation of leading writers' styles as the comprehensive tool to influence the academia, or applying over application of certain features as boosters or hedges to gain attention and integrity via academia. The three fields of education, sociology, and linguistic thought to almost exclusively integrate cognitive development via linguistic relativity enriched through communicative style of writers in different discursive analysis articles.

\section{THEORETICAL FRAMEWORK}

Making a stance by personal style and interpersonal strategies were highlighted by different academia in a variety of disciplines each focusing on "positioning" or "adopting a point of view" (Hyland, 2005, p. 175) exercising devices like stance and engagement features. These devices each comprise different sub factors addressed in detail in Hyland's (2005) and other significant studies that are going to be explained in brief in this section. 


\section{A. Stance}

Relating ones' own authority, opinion, commitments, disguisable involvement, and tentativeness in the texts are expressed by stance features. According to Hyland (2005), it is the ways that "writers intrude to stamp their personal authority onto their arguments or step back and disguise their involvement". He subcategorizes them as hedges, boosters, attitude markers and self mention. (See figure 1).

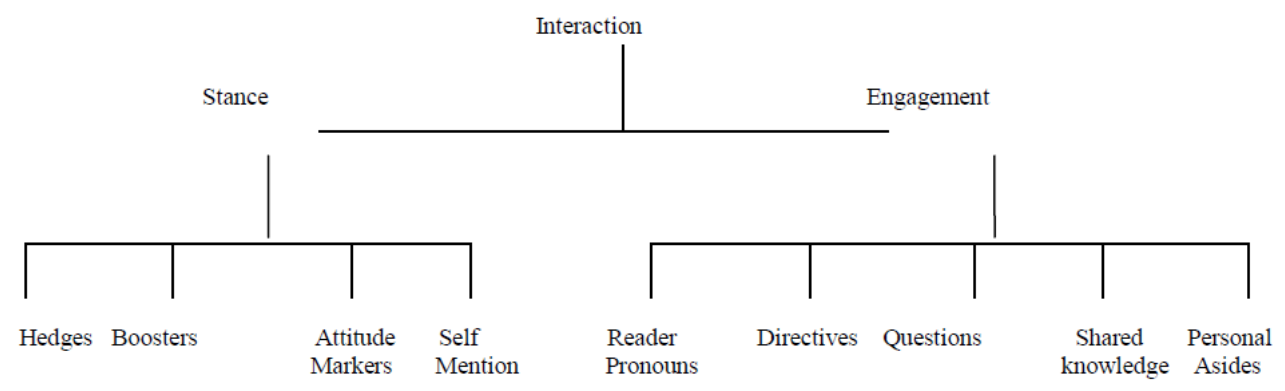

\section{B. Hedges}

Academics are crucially concerned with varieties of cognition, and cognition is inevitably "hedged." Hedging refers to words or phrases "whose job it is to make things fuzzier" (Lakoff 1972: 1951), implying that "the writer is less than fully committed to the certainty of the referential information given" (1994. P. 240). Hyland (1994) asserts that "hedges allow academics to take a rhetorical stance, to downplay their statements and anticipate audience responses by the degree of certainty" (Hyland, 1994, p. 478). According to him, epistemic modality is a central rhetorical means of gaining adherence to knowledge claims and to present them as an opinion than a fact. Hedges refer to possibilities while avoiding direct personal responsibility for one's statements. Slagar- meyer (1994) identifies hedges as "understatements used to convey (purposive) vagueness and tentativeness, and to make sentences more acceptable to the hearer/reader, thus increasing their chance of ratification and reducing the risk of negation". Prince et al (1982) divided hedges into two groups: approximators and shields.

\section{Shield.}

According to Prnice et al (1982), shields express fuzziness in the relationship between the propositional content and the speaker and which therefore deal with the problem from a pragmatic point of view.

\section{Approximators}

Approximators refer to the expressions which change the original meaning of a proposition or provide alternative meaning to the proposition.

\section{E. Boosters}

Salager- Meyer (1997) view the term 'boosters' as those lexical items by means of which the writer can show strong confidence for a claim and Hyland (1998a; 2005) views boosters as "a tool which strengthen the claim by showing the writer's certainty, conviction, and commitment, helping the writers affect interpersonal solidarity". Boosters can therefore help writers to present their work with assurance while effecting interpersonal solidarity, setting the caution and self-effacement suggested by hedges against assertion and involvement.

\section{F. Attitude Markers}

When writers try to convince readers of having an agreement with other researchers while sometimes conveying importance of their work, they may use different comparatives, progressive particles, certain attitude verbs, adjectives or adverbs (e.g. agree, prefer, remarkable, important) to indicate the writer's effectiveness rather than epistemic attitude .

\section{G. Self-mention}

Presence of the writers' identity, style and "interpersonal information" (Hyland, 2001) could be achieved by this feature, the feature in which some academics consciously avoid in order not to make misunderstanding or they suppose that one should use passive verbs as much as they afford to be accepted by discourse community members and their voice could be heard by the whole study's outcomes adopting "disciplinary-situated authorial identity" (Hyland, 2005).

\section{H. Engagement Features}

According to Hyland (2001; 2005), it is the 'alignment dimension where writers acknowledge and connect to others, recognizing the presence of their readers, pulling them along with their argument, focusing their attention, acknowledging their uncertainties, including them as discourse participants, and guiding them to interpretations' (p. 176).His key resources by which these interactional macro-functions were realized are summarized in Figure 1 and the introduction part of all articles were analyzed on the basis of this figure. 


\section{Reader Pronoun}

The feature for an indirect interaction of readers and writers, giving them the right to judge about the whole text while emphasizing their involvement through You and Your- the pronouns that are scarcely used in research articles.

\section{J. Directives}

Different acts are instructed through different kinds of directives in an imperative form. They are mostly used to have an active engagement with the whole corpus, addressing the main point of the study- textual act- and persuading the readers to have a careful activity- physical act- or trying to reason that involvement consciously through cognitive act.

\section{K. Questions}

Dialogic interaction between two partners where the significance of the study is highlighted through invoking the readers' curiosity and interest as well as exploring the addressed issues of the writers in the whole study.

\section{Appeals to Shared Knowledge}

The notion of 'sharedness' is often invoked by writers to smuggle contested ideas into their argument seeking to position readers within apparently naturalized boundaries of disciplinary understandings ( Hyland, 2005). Through this feature, readers are convinced about the uniqueness of the new opinion where influential academics agreed upon.

\section{Personal Asides}

The writers offer their views while acknowledging the previous studies importance directly. The writers in fact try to initiate their interpersonal opinions in each argument with an indirect writer- reader interaction.

Among different stance features, hedges received more influential literature after George Lakoff's (1972) early work on hedges dealing with the words that make things fuzzier or less fuzzy or increase the semantic fuzziness of the sentence. The effective academic writing actually depends on interactional elements which supplement propositional information in the text and alert readers to the writer's opinion. Significant among these interactive elements are hedges (Hyland, 1994).

Prince et al. (1982) found two categories of hedges as approximators and shields, "in the propositional content of the studies. Hyland (1994) examined hedging in 22 textbooks focused on lexical items and found that found that many texts failed to clarify the distinction between epistemic and root modality, thereby confusing possibility with necessity.

Salager-Meyer (1994) analyzed 15 articles and found two-way division between low-hedged methods and results sections as compared to the heavily hedged Introduction and discussion/comment sections of RP and CR. Varttala (1998) investigated hedges in 30 medical articles and found that hedging devices differed according to the communicative situation and lexical hedges occurred in different functions.

Hyland (2000) analyzed the taped interview data and found boosters more visible than hedges and some students tended to shift away from the formulations indicated by the hedges and in another study (2005), he analyzed 240 research articles comprising eight disciplines. He found that questions occurred in the science and engineering papers and reader pronouns frequently used in the soft discipline papers where they appealed to scholarly solidarity, presupposing a set of mutual, discipline-identifying understandings. Shengming (2009) investigated the hedging devices among junior-high, senior-high, and university students and found that the major hedging categories were quantificational approximators, performative shields, modal shields, and pragmatic- marker hedges.

Blagojević (2009) analyzed 45 English and Serbian academic articles in terms of attitude markers and found that by using attitude markers, writers some kind of control over the interpretation of the presented content and suggested cultural, social, and psychological factors embedded in the two writing cultures. Milanovic and Milanovic (2010) investigated 42 business, finance and economics articles. They found high frequency of shields or conventional hedges, especially in the form of modal verbs, they were used to reduce the levels of certainty of the truth of the propositions and also impersonal constructions were used to make references to higher authority.

Hua (2011) recorded 4 college English teachers' classes and found that plausibility shields and adaptors were the two commonly used hedges in the survey and four pragmatic functions of protect face and strengthen cooperation, soften attitude and shorten distance, fill lexical gaps and avoid embarrassment, and improve understanding of culture differences were among the hedges that could foster communication. Abdollahzadeh (2011) studied 60 conclusion sections found higher use of emphatics and attitude markers by American and high avoidance and abstinence from attitudinal language amongst Iranian.

Chang, Luo, and Hsu (2012) investigated attribution hedges in 90 Chinese academic discourse articles and found that "personal attribution" and "impersonal attribution" hedges as both being higher than the "to previous research" and "common knowledge" hedges in the pure humanities and also hard sciences writers demonstrated their objective authorial stance, detachment and avoidance of individuality in their writing. Serholt (2012) studied essays written by Swedish university students and found that females inclined to the propositional information and the male students used hedges more than boosters. Also, both hedges and boosters appeared frequently in the Introduction and Discussion than the remaining sections.

Pishghadam and Norouz Kermanshahi (2012) studied discussion part of 90 teaching and learning English articles. They found that 'textual' stance markers were mostly used in English and Persian articles than 'attitudinal, 'epistemic', 
'causation' and 'deontic' and 'Causation' were mostly used by the Interlanguage writers. Taki and Jafarpour (2012) analyzed 120 research Chemistry and Sociology articles and found that hedges occurred frequently in English articles and attitude marker in Persian articles and regarding self-mentions, they found that unlike English writers who aimed to make an argument stronger through first person pronouns, Persian academics highlighted the phenomena under discussion rather than themselves.

\section{PURPOSE OF THE STUDY}

Stance and engagement features as the strategies to gain acceptance, certainty, and avoidance of certain responsibility had been explored in different domains and disciplines in few studies, (Hyland, 2000, 2005; Serholt, 2012; Pishghadam, \& Norouz Kermanshahi, 2012; Taki \& Jafarpour, 2012). The researchers mostly focused on specific stance feature as hedges and very few on boosters examining the rhetorical structures, style and interpersonal identity features of native and non native writers. To this end, we attempted to explore two specific devices as stance and engagement features as Hyland's (2005) model and Prince et al (1982) classification of hedges in different discourse ISI and non ISI journals. The present study seeks to answer the following questions:

\section{Research Questions}

1. Are there significant differences between stance features of ISI discourse articles with non ISI journals in different fields of sociology, linguistic and education?

2. Are there significant differences between engagement features of ISI discourse articles with non ISI journals in different fields of sociology, linguistic and education?

\section{METHOD}

\section{A. Materials}

In this study, introduction part of 90 articles were randomly selected to investigate the stance markers and stance engagement as the model proposed by Hyland (2005) and prince's and et al (1982) different classification of hedges. Discourse analysis and genre analysis on different disciplines of sociology, education and psychology published from 2004 to 2012 were selected. The whole corpus amounted to 29,005 words in non ISI journals and 33,407 words in ISI journals. Since some leading journals' articles are not open to access, all articles were selected in terms of availability. The classifications of the articles were as follows:

1. 40 articles from ISI journals as English for specific purposes, journal of English for academic purposes, discourse and society, journal of pragmatics, assessing writing, Linguistics and Education, and System in a variety of social science disciplines, including education, sociology and psychology

2. 40 articles in the same disciplines from journals as Reading in a Foreign Language, IBÉRICA, International Journal of Linguistics, Journal of Modern Languages, Journal of Teaching Language Skills, International Journal of Language Studies.

\section{B. Procedure}

Primarily, the introduction parts of ISI journals were analyzed in terms of Hyland's (2005) stance and engagement model, and then non ISI journals were analyzed in two weeks interval to prevent any pre judgment in utilization of different features. Finally, the three fields of the mentioned journals were compared using chi- square test. The whole process of data accumulation and the precise analysis took four months while centralizing on the following properties and their examples:

\section{Stance features:}

A. Hedges: Modal verbs, lexical verbs

a. Shield: seem, appear, suggest, believe, and think. bit, quite

b. Approximate: about, approximately, something between, somehow, some, often, kind of, sort of, really, a little

B. Boosters: Definitely, obviously, certainly, must, should, have to, substantially, exclusively, significantly, and of course

C. Attitude Markers

D. Self Mention

2. Engagement features

a. Reader pronouns: You, your, the reader

b. Directives: Textual act, physical act, cognitive act.

c. Personal aside

d. Appeals to shared knowledge

e. Questions 
In this study, it was attempted to identify different stance and engagement features on the basis of Hyland (2005) model in discourse articles focusing on three fields of linguistics, sociology and education in different ISI and non ISI journals. Chi square test was run to realize the degree of the differences between the stance and engagement features in the most prestigious journals and other journals and we found frequent application of "shield" in linguistics articles and "approximates" like some and somehow in sociology and educational non ISI journals. The other significance was the frequent use of attitude markers in sociological non ISI journals when marginalizing other writers' important works and as it was seen in Table 1, Self mention was the other significant feature applied more in sociological ISI journals (you can compare different features in Table 1). Chi- square result of boosters in ISI and non ISI journals was not significant.

TABLE 1.

FREQUENCY AND CHI- SQUARE RESULTS OF SOCIOLOGY ISI AND NON ISI STANCE FEATURES

\begin{tabular}{|c|c|c|c|c|c|c|}
\hline \multicolumn{2}{|c|}{ Discourse Articles } & \multicolumn{2}{|c|}{ Sociology: Observed } & \multirow[t]{2}{*}{ Expected } & \multirow[t]{2}{*}{$x^{2}$} & \multirow[t]{2}{*}{ Asymp. sig } \\
\hline & & ISI & Non ISI & & & \\
\hline \multirow[t]{2}{*}{ Hedges } & Shield & 107 & 117 & 112.0 & .446 & .504 \\
\hline & Aprox & 45 & 71 & 58.0 & 5.828 & .016 \\
\hline \multicolumn{2}{|c|}{ Boosters } & 61 & 58 & 59.5 & .076 & .783 \\
\hline \multicolumn{2}{|c|}{ Attitude markers } & 12 & 34 & 23.0 & 10.522 & .001 \\
\hline \multicolumn{2}{|c|}{ Self mention } & 78 & 50 & 64.0 & 6.125 & .013 \\
\hline
\end{tabular}

Chi- square results revealed that "Shield", boosters, and self mention were among the features practiced more in ISI journals. Attitude markers and approximates were detected more in non ISI linguistic journals (see Table 2).

TABLE 2.

REQUENCY AND CHI- SQUARE RESULTS OF LINGUISTIC ISI AND NON ISI STANCE FEATURES

\begin{tabular}{|l|l|l|l|l|l|l|}
\hline \multicolumn{2}{|l|}{ Discourse Articles } & Linguistic: Observed & Exp & $x^{2}$ & Asymp. sig \\
\hline \multicolumn{2}{|l|}{ Hedges } & ISI & Non ISI & & & \\
& Shield & 140 & 118 & 129.0 & 1.876 & .171 \\
\cline { 2 - 7 } & Aprox & 36 & 52 & 44.0 & 2.909 & .088 \\
\hline Boosters & 67 & 53 & 60.0 & 1.663 & .201 \\
\hline Attitude markers & 18 & 23 & 20.5 & .610 & .435 \\
\hline Self mention & 43 & 31 & 37.0 & 1.946 & .163 \\
\hline
\end{tabular}

In terms of Educational articles, the differences were explored more in exercising "boosters" and "self mention" in ISI journals (see Table 3). Other features in educational articles were not statistically significant.

TABLE 3.

REQUENCY AND CHI- SQUARE RESULTS OF EDUCATION ISI AND NON ISI STANCE FEATURES

\begin{tabular}{|l|l|l|l|l|l|l|}
\hline \multicolumn{2}{|l|}{ Discourse Articles } & Education: Observed & Exp & $x^{2}$ & Asymp. sig \\
\hline \multicolumn{2}{|l|}{ Hedges } & ISI & Non ISI & & & \\
\cline { 2 - 7 } & Shield & 123 & 120 & 129.0 & 1.876 & .171 \\
\hline Boosters & 46 & 53 & 49.5 & .495 & .482 \\
\hline Attitude markers & 80 & 48 & 64.0 & 8.000 & .005 \\
\hline Self mention & 28 & 20 & 24.0 & 1.333 & .248 \\
\hline
\end{tabular}

TABLE 4.

REQUENCY AND CHI- SQUARE RESULTS OF ISI AND NON ISI ENGAGEMENT FEATURES IN SOCIOLOGY

\begin{tabular}{|l|l|l|l|l|l|}
\hline Discourse Articles & \multicolumn{2}{|l|}{ Sociology Observed } & Exp & $x^{2}$ & Asy. sig \\
\hline & ISI & Non ISI & & & \\
\hline Reader Pronoun & 9 & 41 & 25.0 & 20.480 & .000 \\
\hline Directives & 14 & 6 & 10.0 & 3.200 & .074 \\
\hline Personal Aside & 16 & 25 & 21.0 & 1.524 & .217 \\
\hline Appeals to Shared Knowledge & 10 & 21 & 15.5 & 3.903 & .048 \\
\hline Question & 13 & 6 & 9.5 & 2.579 & .108 \\
\hline
\end{tabular}

"Directives" and "appeals to shared knowledge" were two significant differences in applying different engagement features in sociological articles and "reader pronouns" were the most engagement features applied in Non ISI sociology (See Table 4). In Linguistic articles, "Personal aside" and "appeals to shared knowledge" were among the features exercised more in non ISI journals except for the significance of "questions" in ISI journals (see Table 5).

TABLE 5.

REQUENCY AND CHI- SQUARE RESULTS OF ISI AND NON ISI ENGAGEMENT FEATURES IN LINGUISTICS

\begin{tabular}{|l|l|l|l|l|l|}
\hline Discourse Articles & \multicolumn{2}{|l|}{ Linguistic: Observed } & Exp & $x^{2}$ & Asy. sig \\
\hline & ISI & Non ISI & & & \\
\hline Reader Pronoun & 4 & 9 & 6.5 & 1.923 & .166 \\
\hline Directives & 6 & 5 & 5.5 & .091 & .763 \\
\hline Personal Aside & 17 & 28 & 22.0 & 2.273 & .132 \\
\hline Appeals to Shared Knowledge & 12 & 30 & 21.0 & 7.714 & .005 \\
\hline
\end{tabular}


In the last table, you can kindly distinguish the significance in applying "personal aside" and "questions" features in ISI journals and "appeals to shared knowledge" in non ISI journals of educational field (See Table 6).

TABLE 6.

REQUENCY AND CHI- SQUARE RESULTS OF ISI AND NON ISI ENGAGEMENT FEATURES IN EDUCATION

\begin{tabular}{|l|l|l|l|l|l|}
\hline Discourse Articles & \multicolumn{2}{|l|}{ Education: Observed } & Exp & $\boldsymbol{x}^{2}$ & Asym.sig \\
\hline & ISI & Non ISI & & & \\
\hline Reader Pronoun & 15 & 12 & 13.5 & .333 & .564 \\
\hline Directives & 8 & 3 & 5.5 & 2.273 & .132 \\
\hline Personal Aside & 26 & 18 & 22.0 & 1.455 & .228 \\
\hline Appeals to Shared Knowledge & 24 & 40 & 32.0 & 4.000 & .046 \\
\hline Question & 14 & 7 & 10.0 & 2.333 & .127 \\
\hline
\end{tabular}

Different presentations of hedges as modal and lexical verbs could be perceived in Appendix A. Concerning modal verbs, "can" was more significantly used in both ISI and Non ISI journals and "may" occurred more significantly in sociological and educational ISI journal and "Could" was more frequent in non ISI linguistic articles. Considering lexical verbs, "appear" was more significant in ISI linguistic articles while "think" was more significant in educational ISI journals.

\section{Discussion AND CONCLUSION}

In this study, it was intended to realize the stance and engagement differences between the introduction parts of three fields of sociology, linguistic and education discourse articles and regarding the first question of this study of finding the significant differences between stance features of prestigious journals in which different researchers all over the world try to publish their works by and other journals ,the results revealed significant differences in different features of stance and engagement model as was first frameworked by Hyland (2005).

Undoubtedly, most writers develop their own style of persuasion "while trying to control the personal and cultural identity they are projecting in their writing" (Hyland, 2008) but each language rhetorical structures could be indirectly enhanced in academic writing where features like "self mention" as a "central pragmatic feature of academic discourse contributes not only to the writer's construction of a text, but also of a rhetorical self" (Hyland, 2002, p. 1110). This feature was frequently used by different writers except for Persian articles where writers mostly preferred to use passive verbs as far as they could and scarcely used self mention to project the 'indirectness of their rhetorical structures and their cautious style when expressing opinion" (Scollon,1994; Hinkel, 1997, 2002).

In Sociological articles the intention was observed more in applying self mention feature in ISI journals and though Harwood (2005 a) asserts that personal pronouns are used as marketing tactics to promote one's work in competitive world of academia, we believe that they were one of exclusive features to strengthen the writers' significance presence in the study, to promote the underlying new rhetoric under study, and to highlight the socio- psychological nature of the writers' ego identity and as Tang and John (1999) stated, the first person pronoun is not a "homogeneous entity", but instead it can help to project a number of different roles or identities with varying degrees of authorial presence. This authorial presence was one of the features of ISI journals that made the significance toward non ISI journals and though Scollon (1994) suggests that the use of first person pronouns is largely unacceptable in the traditions of Asian cultures because of its association with individual rather than collective identity, it seems that publishing in prestigious journals helps to exercise more self confidence to share the uniqueness of the study via first or plural person pronouns and crosses the boundary of culture and nations since we observed Asian writers' practicing self mention when publishing in ISI journals.

The crucial emphasis in practicing "shields" and more specifically on modal verbs like "can" in all fields of study was scrutinized to lessen the vagueness and tentativeness of the other modal verbs. "May" was marginalized in ISI journals not only to express the writers' "due caution, modesty, and humility, and to negotiate diplomatically to the work of colleagues and competitors" (Hyland, 1994) but also it had underlying précised authorial property to first direct the readers' attention to have some comparison between the present study and the literature reviewed in the study while not taking any full responsibility of the asserted previous literature and second to preserve their face and to have some pleasant truce with other researchers and avoid any open contradiction. "Could" as the most tentative modal verbs (Hyland 1994) was significant in non ISI linguistic articles to hasten the tentativeness of the arguments.

Concerning lexical verbs, "appear" was a significant lexical verb in just linguistic and "think" in educational ISI articles. It seemed that linguistic articles had a strong tendency to enhance the vagueness of the claims and educational one strengthened the cognitive structures of the whole projects. They all actually invited the readers and professional researchers to correspond to the vagueness and the tentativeness of the study more collaborately. This vagueness sometimes may confuse the students as being an authorial structure or modesty feature that should be developed in any academic writing since even great figures in academia continuously practiced it in their writings and so some students may blindfully motivate to exercise it as both a fashion style and a crucial need to be accepted among discourse community members.

Approximators as the "institutionalized" language of science (Slager meyer, 1994) were significant more in non ISI journals focusing on words like "some" and "somehow", "often", and "about" and served to clarify the unknown and 
unavailable properties of other researches when at the same time highlighting the strength of the underlying features and constructs of the study. Approximates like "sort of, entirely, a little bit, roughly and approximately" were never found in ISI all three fields of study. The significant difference between the application of approximators in ISI and non ISI journals could be traced back to the socio- cultural differences of writers and their most attempts to highlight the vagueness of the literature while indirectly impose their being independent from it.

Boosters as the second frequent feature in experimental literature was significant in educational ISI journals in comparison to non ISI ones and specifically the use of "must and should" was significant in educational ISI journals and also the marginalized application of "no one" and "no" to express the previous literature's lacks was among the significant features developed in both ISI and non ISI journals. Educational articles seemed to develop some kind of authorial self and practice power when viewing the students or readers to do some do's and don'ts while calling for cooperation and partnership at the same time and like hedges they practiced the persuasion while' allowing writers to express their thorough certainty and marking involvement with the audience and the topic alike" (Hyland, 2005). This powerful certainty was clearly pinpointed in the following examples:

Students must have knowledge of these taxonomies in order to follow the sequential steps in the solution.......

A progressive pedagogical approach and theory of learning must be accompanied by compatible ideologies of learning shared by students, teachers, and policy makers alike.

Along with hedges, they were used to make a balance between full certainty and assertiveness of the claims as well as their vagueness as the cautious devices of not taking full responsibility of the asserted discussions to convince the audience either from academia or novice students. . Though some times in educational articles the excessive use of boosters and hedges_ in just the introduction parts of ISI journals_may lead to inconsistency where it may confuse the readers whether question the underlying arguments or peacefully accept them while negotiating with the main claims. This confusion could be best exemplified in the following sentences:

Writers may presume certain beliefs to be shared that may not in fact be held in common or maynot generally accepted. These beliefs will not be asserted, ..

It should be taken into consideration that these analyses may be contaminated by possible individual predispositions.

Regarding the second research questions in realizing the significance of ISI and non ISI journals considering engagement features, we found that "reader pronouns" were among the least features in three fields under study in "supporting the writer's position and building writer-reader relationships" (Hyland, 1994, p. 241) and though he asserts that we cannot find the pronoun "You" in academic writings and writers use the pronoun "We" instead to bind readers and writers but except for the very few, most first person pronouns that were detected in the introduction parts of linguistic and educational discourse articles were to emphasize the joint attempts of writers to execute certain measures. The significance was just identified in sociological non ISI journals that attempted to emphasize the sociable nature of these articles in enhancing group work, sharedness of reader and writers through the frequent application of "you" and "we". The other lacks was the single concentration of "textual acts" as one of the classifications of "directives" in engagement features "directing readers to a reference rather than informing them how they should interpret an argument" (Hyland, 2005). They were mostly marked in sociological ISI articles enhancing social relationships with the readers and they were practiced least in non ISI educational articles. Two features of physical and cognitive acts were totally ignored in most discourse articles and it seemed that the nature of these fields may maintain writer oriented with less cognitive interaction of readers and writers.

"Attitude markers", "personal aside" and "appeals to shared knowledge" were among the features practiced in all articles. All practiced these features to express commitment to theoretical and experimental literature while searching the degree of truth to persuade the genuineness of the study. Over perseverance of these features in non ISI journals could be interpreted as being over dependent to popular writers' statements as the best engagement features with less self confidence to project one's own texts in at least the introduction parts of the study. Over statements and misuse of influential writers' statements could express modesty and respectfulness toward them, try to meet the expectations of the expert readers, and to urge the uniqueness of the study but at the same time may question the professional adequacy and capabilities of the writers. So "all writers need to rely to a greater extent on a personal projection into the text through self-mention and attitude markers to invoke an intelligent reader and credible collegial writers" (Hyland, 2005, p. 188).

Though research objectives could be easily frameworked and developed within the research questions and they are one of the exclusives that could illustrate the" main problems of the study, study's design, and the types of the instruments (Onwuegbuzie and Leech, 2006; Tabane et al, 2009), they were less marginalized in non ISI articles. Some of them may either neglect the significance of research questions in building open relationships and dialogic interaction with the readers in determining an organized preconceptions about developmental process of the claims or might concede the whole undertakings on readers to develop the whole study's tentative hypotheses, evaluate the procedures and predict the outcomes without posing rhetorical questions in qualitative or quantitative investigations.

Stance and engagement features are necessary devices bonding readers-writers' interaction, group work, and negotiation of meaning. Significant differences explored in different stance and engagement features namely hedges occurring more frequently in linguistic articles, boosters and "attitude markers" in educational articles, and self mention in sociology articles. This significance may confuse the novice readers to either embed as hedges and boosters or other features that they could to empress the academia or develop their own style. In other words whether the writers should 
practice authorial self and power over readers or indicate their modesty and honesty that neither" nullifies other feature's influence" (Jalilifar, 2010) nor practice over boosterization or over hedges-ization. Though the second option may seem convenient, many students follow the same path of specific pieces of writings as the best stance without substantial instructions. It seems necessary to highlight socio- cultural impressions of these features on construction of rhetorical understandings of the students and to develop an exclusive content providing the students with subtle interactive stance and engagement features necessary in promoting the writers' discursive persona in academia.

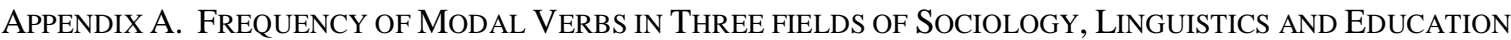

\begin{tabular}{|c|c|c|c|c|c|c|c|c|c|c|}
\hline Discourse Articles & \multicolumn{10}{|c|}{ Hedges } \\
\hline \multirow[t]{3}{*}{ Type } & \multicolumn{10}{|c|}{ Modal Verbs } \\
\hline & \multicolumn{2}{|c|}{ May } & \multicolumn{2}{|c|}{ Might } & \multicolumn{2}{|c|}{ Can } & \multicolumn{2}{|c|}{ Could } & \multicolumn{2}{|c|}{ Would } \\
\hline & ISI & Non ISI & ISI & Non ISI & ISI & Non ISI & ISI & Non ISI & ISI & Non ISI \\
\hline Sociology & 24 & 6 & - & 4 & 39 & 28 & 4 & - & 8 & 6 \\
\hline Linguistics & 12 & 16 & 10 & 3 & 42 & 31 & 3 & 12 & 8 & 2 \\
\hline Education & 22 & 6 & 1 & 4 & 41 & 32 & 3 & 1 & 3 & 5 \\
\hline
\end{tabular}

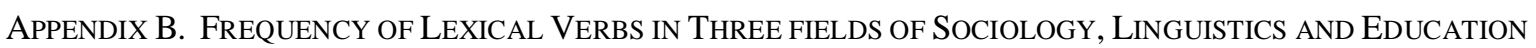

\begin{tabular}{|c|c|c|c|c|c|c|c|c|c|c|c|c|}
\hline \multirow{4}{*}{$\begin{array}{l}\text { Discourse Articles } \\
\text { Type }\end{array}$} & \multicolumn{12}{|c|}{ Hedges } \\
\hline & \multicolumn{12}{|c|}{ Lexical Verbs } \\
\hline & \multicolumn{2}{|c|}{ Seem } & \multicolumn{2}{|c|}{ Appear } & \multicolumn{2}{|c|}{ Suggest } & \multicolumn{2}{|c|}{ Indicate } & \multicolumn{2}{|c|}{ Believe } & \multicolumn{2}{|c|}{ Think } \\
\hline & ISI & Non ISI & ISI & Non ISI & ISI & $\begin{array}{l}\text { Non } \\
\text { ISI }\end{array}$ & ISI & $\begin{array}{l}\text { Non } \\
\text { ISI }\end{array}$ & ISI & $\begin{array}{l}\text { Non } \\
\text { ISI }\end{array}$ & ISI & $\begin{array}{l}\text { Non } \\
\text { ISI }\end{array}$ \\
\hline Sociology & 2 & 7 & 4 & 3 & 4 & 10 & - & 1 & 2 & 3 & 1 & 5 \\
\hline Linguistics & 5 & 8 & 12 & 2 & 8 & 7 & 4 & 2 & 2 & 2 & 1 & 1 \\
\hline Education & 5 & 3 & 2 & 1 & 9 & 8 & 8 & 6 & 1 & 7 & 14 & 6 \\
\hline
\end{tabular}

\section{REFERENCES}

[1] Abdollahzadeh, E. (2011). Poring Over the Findings: Interpersonal Authorial Engagement in Applied Linguistics Papers. Journal of Pragmatics, 43, 288-297.

[2] Chang, M., \& Luo, Y., \& Hsu, Y. (2012). Subjectivity and Objectivity in Chinese Academic Discourse: How Attribution Hedges Indicate Authorial Stance. Concentric: Studies in Linguistics, 38(2), 293-329.

[3] Crompton, P. (1997). Hedging in Academic Writing: Some Theoretical Problems. English for Specific Purposes, 16(4), 271287.

[4] Harwood, N. (2005). A Corpus-based Study of Self-promotional I and We in Academic tingwri Across Four Disciplines. Journal of Pragmatics, 1-25.

[5] Hua, J. (2011). A Study on Pragmatic Functions of Hedges Applied by College English Teachers in the Class. M \& D FORUM, Proceedings of the Fourth International Symposium on Education Management and Knowledge Innovation Engineering , 562566.

[6] Hyland, K. (1994). Hedging in Academic Writing and EAP Textbooks. English for Specific Purposes, 13(3), 239-256.

[7] Hyland, K. (1996). Nurturing Hedges in the ESP Curriculum. System, 24 (4), 477-490.

[8] Hyland, K. (2000). Hedges, Boosters and Lexical Invisibility: Noticing Modifiers in Academic Texts. Language Awareness, 9 (4), 179-197.

[9] Hyland, K. (2001). Bringing in the Reader: Addressee Features in Academic Writing. Written Communication, 18(4), 549-74.

[10] Hyland, K. (2002). Authority and Invisibility: Authorial Identity in Academic writing. Journal of Pragmatics, 34, 1091-1112.

[11] Hyland, K. (2005). Stance and engagement: a Model of Interaction in Academic Discourse. Discourse Studies, 7(2): 173-192.

[12] Hyland, K. (2008). Persuasion, Interaction and the Construction of Knowledge: Representing Self and Others in Research Writing. IJES, $8(2), 1-23$.

[13] Jalilifar, A. (2010). World of Attitudes in Research Article Discussion Sections: A Cross-Linguistic Perspective. Journal of Technology \& Education, 5, (3), 177-186.

[14] Lakoff, G. (1972). "Hedges: a Study in Meaning Criteria and the Logic of Fuzzy Concepts." Journal of Philosophical Logic, 2 , 458-508.

[15] Milanovic, M., \& Milanovic, A. (2010). Softening the Words of Crises: Hedging in Economics- Related Articles Published on the Internet. Ekonomski Horizonti, 12, (1), 121-129.

[16] Onwuegbuzie, A.J., \& Leech, N.L. (2006). Linking Research Questions to Mixed Methods Data Analysis Procedures. The Qualitative Report, 11 (3), 474-498.

[17] Pishghadam, R., \& Norouz Kermanshahi, P. (2012).Writers' Stance-taking in EFL Articles: A Case of Persian, English and EFL Speakers. The Iranian EFL Journal, 8 (5), 9-22.

[18] Prince, E.F., \& Frader, R. J., \& Bosk, C. (1982). "On hedging in physician-physician discourse." In J. di Prieto (Ed.) Linguistics and the Professions. (pp. 83-97). Ablex Publishing Corporation. 
[19] Serholt, S. (2012). Hedges and Boosters in Academic Writing. A Study of Gender Differences in Essays Written by Swedish Advanced Learners of English. Unpublished Thesis, Engelska.

[20] Shengming, Y. (2009). The Pragmatic Development of Hedging in EFL Learners. Unpublished Phd Dissertation, University of Hong Kong.

[21] Salager-Meyer, F. (1994). Hedges and Textual Communicative Function in Medical English Written Discourse. English for Specific Purposes, 13 (2), 149-171.

[22] Scollon, R. (1994). As a Matter of fact: the Changing Ideology of Authorship and Responsibility in discourse. World Englishes $13,34-46$.

[23] Thabane, L., \& Thomas, T., \& Chenglin, Y., \& Paul, J. (2009). Posing the Research Question: Not so Simple. Can J Anesth, 56, 71-79.

[24] Taki, S., \& Jafarpour, F. (2012). Engagement and Stance in Academic Writing: A Study of English and Persian Research Articles, Mediterranean Journal of Social Sciences, 3 (1), 157-168.

[25] Tang, R., \& Suganthi, J. (1999). The 'I' in Identity: Exploring Writer Identity in Student Academic Writing Through the First Person Pronoun. English for Specific Purposes 18, S23-S39.

[26] Varttala, T. (1999). Remarks on the Communicative Functions of Hedging in Popular Scientific and Specialist Research Articles on Medicine. English for Specific Purposes, 18 (2), 177-200.

Leila Sayah is a Phd student at Ferdowsi University of Mashhad- Iran. She teaches at Farhangian University of Ahwaz, Iran and other universities. Her major research interests include discourse analysis and TEFL.

Mohammad Reza Hashemi is an associate professor in Applied Linguistics. He is currently at Ferdowsi University of Mashhad, Iran where he teaches translation studies and discourse analysis. His areas of interest include translation studies, discourse analysis, and CDA. 